\title{
Lipids Composition in Plant Membranes
}

\author{
Emilia Reszczyńska (i] ${ }^{1} \cdot$ Agnieszka Hanaka ${ }^{1}$
}

Accepted: 22 September 2020 / Published online: 9 October 2020

(c) The Author(s) 2020

\begin{abstract}
The paper focuses on the selected plant lipid issues. Classification, nomenclature, and abundance of fatty acids was discussed. Then, classification, composition, role, and organization of lipids were displayed. The involvement of lipids in xantophyll cycle and glycerolipids synthesis (as the most abundant of all lipid classes) were also discussed. Moreover, in order to better understand the biomembranes remodeling, the model (artificial) membranes, mimicking the naturally occurring membranes are employed and the survey on their composition and application in different kind of research was performed. High level of lipids remodeling in the plant membranes under different environmental conditions, e.g., nutrient deficiency, temperature stress, salinity or drought was proved. The key advantage of lipid research was the conclusion that lipids could serve as the markers of plant physiological condition and the detailed knowledge on lipids chemistry will allow to modify their composition for industrial needs.
\end{abstract}

Keywords Fatty acid $\cdot$ Lipid $\cdot$ Membrane $\cdot$ Plant

Plants are constantly exposed to stress resulting from the conditions in which they are growing. They have to adapt to the external changes like humidity, salinity, or temperature. In order to maintain the normal physiological function and survive in the unfavorable environmental conditions, plants have developed defense mechanisms. Among them are alterations in the content of lipids, proteins or other molecules. For example, some of the plants are sensitive to temperature changes, e.g., Cucumis sativa L. [1] or Solanum lycopersicum L. [2], whereas others are less sensitive to temperature fluctuations, e.g., Arabidopsis thaliana L. [3] or Spinacia oleraceae L. These differences could be partially explained by the quantitative and qualitative changes in the lipid composition, which in turn triggers membrane fluidity and its function. Therefore, it is worth to present the selected lipid issues with the aim of explaining differences

Emilia Reszczyńska

e.reszczynska@poczta.umcs.lublin.pl

1 Department of Plant Physiology and Biophysics, Institute of Biological Sciences, Faculty of Biology and Biotechnology, Maria Curie-Sklodowska University, 20-033 Lublin, Poland in their content, specific role in plants and emphasizing their impact in adverse conditions.

\section{Classification of Fatty Acids in Plants}

Nowadays, structure and role of about 400 different fatty acids are known in the plant kingdom [4]. Some of them are inevitable in the proper function of plant cells and some have positive effects on human health (e.g., antiinflammatory [5-7], anticancer [8, 9], antibacterial [10], and antiparasitic activity [11]) or are demanded in the different branches of industry, like food, pharmaceuticals, and cosmetics production [12-14].

The plant membranes are composed mainly of lipids which possess a hydrophilic, polar head attached to a glycerol backbone and a hydrophobic tail built of two fatty acids. Lipids form a hydrophobic barrier that separates cells and organelles from the environment $[15,16]$. The core building block of fatty acids is a hydrocarbon chain with a carboxyl group (-COOH) located on its terminal end. Based on the chain length of fatty acids, they are classified as: short-chain (aliphatic tails of up to 5 or even 7 carbons), medium-chain (aliphatic tails of 6-8 up to 12-14 carbons), long-chain (aliphatic tails of 13-18 up to 22 carbons), or very long-chain fatty acids (aliphatic tails longer than 22 carbons; >C22) [17-21]. Most often, the number of carbon 
atoms in the plant tissues is between 14 and 24. Moreover, the aliphatic chain can be saturated (saturated fatty acid, SFA) or unsaturated (unsaturated fatty acid, UFA), where all carbon-carbon linkages form single bonds, or some carbons are matched by one or more double bonds, respectively. In addition, UFA can be divided into monounsaturated (monoenoic) fatty acids (MUFA) and polyunsaturated fatty acids (PUFA) with exactly one or at least two double bonds, respectively [22, 23]. Fatty acids are the building blocks of lipids.

\section{Nomenclature of Fatty Acids}

According to the International Union of Pure and Applied Chemistry (IUPAC) nomenclature of fatty acids, they can be formed using three systems of rules known as the shorthand formulas, the systematic names and the trivial names. The triple nomenclature can be demonstrated on one of the saturated fatty acids: C16:0 — shorthand formula; hexadecenoic acid—systematic one; palmitic acid—trivial name. More complicated names can be constructed for the MUFA and PUFA, where one or more double bounds in acyl chain occur. In the case of the fatty acid possessing one double bound, C16:1 (n-7), it can be denoted as cis-hexadec-9-enoic acid (systematic formula) or palmitoleic acid (trivial name) [24]. For PUFA, two examples with different numbers of double bonds in the molecule are shown below in order to clarify the nomenclature. $\alpha$-linolenic acid with the cis double bond located at the third region in carbon atom (n-3) marked from the end with methyl group is described as the omega $(\omega)-3$ with the general structure $\mathrm{CH}_{3} \mathrm{CH}_{2}\left(\mathrm{CH}=\mathrm{CHCH}_{2}\right)_{n} \mathrm{COOH}$, where $n$ shows the numbering of cis double bond from the methyl terminus $[24,25]$. In addition, the position of the double bond in the carbon chain can be designated by delta $(\Delta)$ before the full name of fatty acid, counting carbons from the carboxyl group [26, 27]. Linoleic acid (C18:2) with 18 carbon chain and two cis double bonds at C-9 and C12 from the carboxyl acid group could be specified as: 18:2 cis- $\Delta^{9}$, cis- $\Delta^{12}$ octadecadienoic acid; cis, cis-9,12-octadecadienoic acid or cis,cis-6,9-octadecadienoic acid. Sometimes PUFA are designated without $\omega$ (C18:3), but it is unequivocal and can be represented by a few different fatty acids: C18:3 $\omega 1$, $\mathrm{C} 18: 3 \omega 3, \mathrm{C} 18: 3 \omega 6$, or $\mathrm{C} 18: 3 \omega 9$ [22, 23, 28]. The systematic names of fatty acids are derived from the names of the main straight chain by the substitution of suffix -e with -oic, e.g., hydrocarbon chain of $\mathrm{C} 18$ saturated fatty acid is octadecane and the acid is called octadecanoic acid (C18:0) [22]. The exemplary formula of fatty acid was presented in Fig. 1. Some trivial names of fatty acids origin from their natural sources, like palmitic acid, which was detected as a palm oil component; oleic acid $\left(\mathrm{C} 18: 1 \mathrm{cis}-\Delta^{9}\right)$ —occurred in a oleic acid
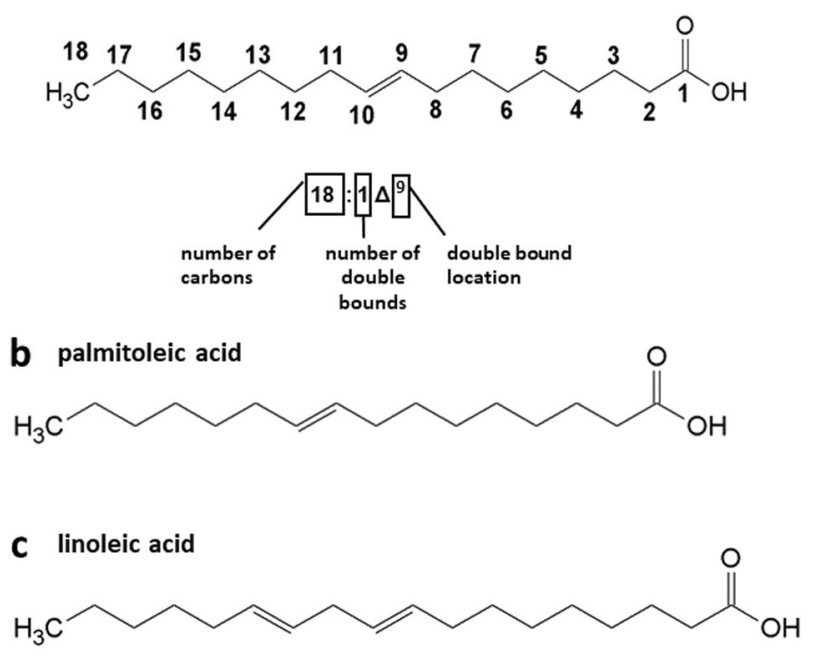

d $\alpha$-linolenic acid

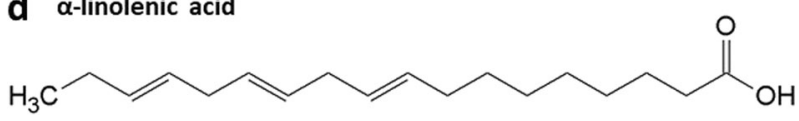

Fig. 1 Exemplary formula of fatty acids. Fatty acids are numbered from $-\mathrm{COOH}$ group $(\Delta)$ and from $-\mathrm{CH}_{3}$ group $(\omega)$. a Cis-oleic acid18:1-is with one double bound $\Delta^{9}$ (IUPAC: (9Z)-Octadec-9-enoic acid), b palmitoleic acid-16:1-is with one double bound $\Delta^{9}$ (IUPAC: (9Z)-Hexadec-9-enoic acid), c linoleic acid-18:2-is with two double bounds $\Delta^{9,12}$ (IUPAC: 9-cis,12-cis octadecadienoic acid), d $\alpha$-linolenic acid-18:3-is with tree double bounds $\Delta^{9,12,15}$ (IUPAC: (9Z,12Z,15Z)-octadec-9,12,15-trienoic acid)

olive oil [24] and myristic acid (tetradecanoic acid)—was first identified in the Myristicaceae family [29].

\section{Fatty Acids Composition in Plants}

Some of the plant families are more often implemented into the research on fatty acids. Among them are Fabaceae and Asteraceae. To the Fabaceae belong, i.e., Arachis hypogaea L. [30], Astragalus L. [31], Pisum sativum L. [32], and to Asteraceae: Anthemis altissima L. [33], A. arvensis L. [34], A. talyschensis L. [35], Chamaemelum nobile L. [36], Tagetes patula L. [37]. Other families also have their representatives in the experiments on lipids, e.g., Lauraceae with Cinnamomum camphora and Umbellularia californica [31], Vitaceae with Cissus populnea Guill. and Perr. [31], Polygonaceae with Fagopyrum esculentum and Brassicaceae with Arabidopsis thaliana. Species listed above are used in pharmacy and medicine, e.g., Astragalus (recommended in immune disorders) [31] and A. altissima (possess sedative, digestive and antimicrobial activity) [38-40]; nutrition, e.g., A. hypogaea, F. esculentum (applied in human diet); industry, e.g., C. camphora and U. californica 
(both used in biodiesel production, especially C12:0-14:0) [17]; and the research, e.g., A. thaliana [41].

The summary of various plant families, species and plant parts (such as the seeds, leaves, flowers, stem oils, and roots) in Table 1 shows the considerable quantitative and qualitative differences in the fatty acids composition. Below are presented some specific examples concerning the seeds, aerial parts, leaves, flowers, and leafy stems.

The same parts of the different plants can vary significantly in the composition of fatty acids, e.g., in seeds. The seeds of peanuts (A. hypogaea) contained the highest amounts of oleic $(\mathrm{C} 18: 1)$ and linoleic $(\mathrm{C} 18: 2)$ acids reaching $50 \%$ and $30 \%$, respectively [30]. In the essential oil from the aerial parts of $A$. arvensis, the palmitic acid achieved $21 \%$ [42], whereas $8.8 \%$ in the seeds with the total PUFA/SFA ratio equal 7.17 [34]. In the seeds of $C$. populnea, the most abundant among fatty acids were palmitic (C16:0)-40\%, oleic (C18:1n-9)-27\%, stearic (C18:0) - 16.5\%, and linoleic (C18:2n-6)-11.86\% acids. Oil from the $C$. papulnea seeds contained SFA, which makes it appropriate for frying food because it is stable at increasing temperatures and stay resistant to oxidation [43]. The highest relative content of fatty acids in the F. esculentum seeds was determined for linoleic (C18:2n-6) (in the range 35.54-47.57\%), oleic (C18:1n-9) (in the range 20.96-40.76\%), and palmitic (C16:0) (in the range 13.86-26.42\%) acids and the range of their values was dependent on the plant part (whole grain, hulls and bran). In addition, other fatty acids were identified in smaller quantities, i.e., lauric (C12:0), myristic (C14:0), palmitoleic (C16:1), stearic (C18:0), $\alpha$-linolenic (C18:3n-3), and arachidic (C20:0) acids [44]. Moreover, $\alpha$-linoleic acid is a precursor of the phytohormone, jasmonic acid, which is involved in the response of plants to the biotic and abiotic stress conditions [30]. Furthermore, both in the transgenic and non-transgenic seeds of $A$. thaliana the most abundant fatty acids were 18:2 ( 30\%) and 18:3 ( 19\%) [30] and the PUFA/SFA ratio was 4.05 [34].

The leaves of plants like $C$. camphora and $U$. californica in the presence of thioesterases accumulated 52 and $40 \%$ of C12:0 and C14:0, respectively, which protected plants against the fatty acids modification and deprivation of the membrane homeostasis. Triacylglycerols compose the fatty acids, e.g., C12:0, C14:0, C16:0, but their proportion depends on the expression or co-expression of thioesterases in the plants. Fatty acids are very important during modification of the lipid profiles in the plant membranes because their unbalance causes undesirable chlorosis and cell death [17]. In A. talyschensis, the composition of fatty acids depended on the plant part, thus SFA in the flowers was $1.3 \%$ and in the leaves-9.4\% and UFA was $17.7 \%$ in the flowers and $87.0 \%$ in the leaves-being not detected in the stem. The proportion of PUFA/SFA in the flowers and

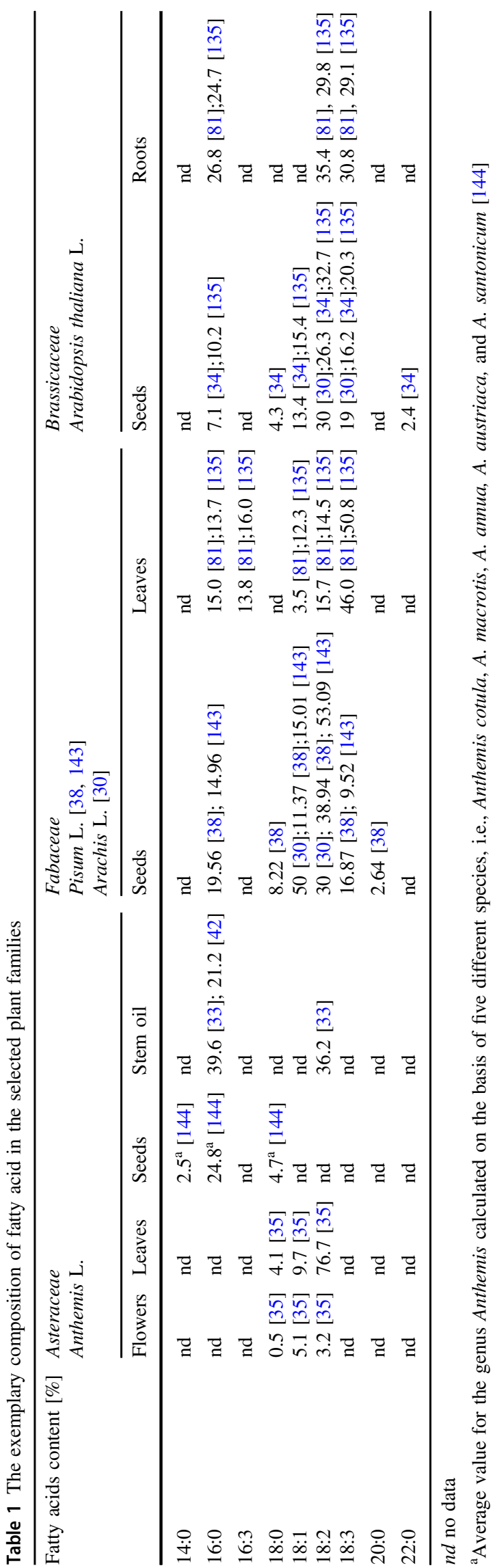




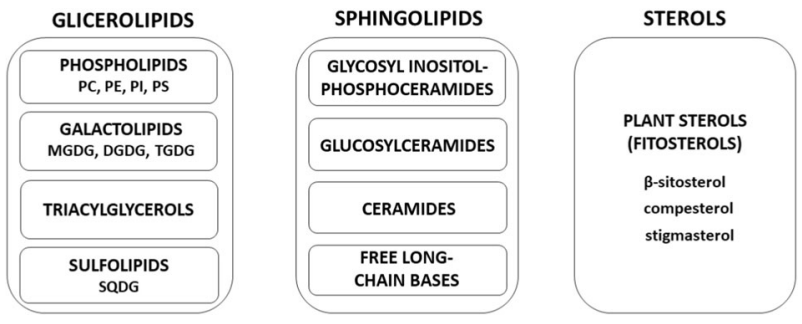

Fig. 2 Classification of plant membrane lipids [142]

leaves was 13.62 and 9.25, respectively [35]. In addition, both leafy stems and flowers of $C$. nobile contained fatty acids: C16:0 ( 18\%), C18:1n-9 ( 23\%), C18:2n-6 ( 29\%), C18:3n-3 ( 18\%), and the proportion of PUFA/SFA was $1.72[36]$.

\section{Classification and Composition of Lipids in Plants}

In the plant membranes, three main classes of lipids appear, i.e., glycerolipids, sphingolipids, and sterols (Fig. 2). The most abundant are glycerolipids, which are divided into four groups: phospholipids (PL), galactolipids (GL), triacylglycerols (TAG), and sulfolipids (SL) [45, 46]. Phospholipids containing phosphorus are major constituents of the membranes and they have different head groups modified by choline, ethanolamine, serine, or inositol and are described as phosphatidylcholine (PC), phosphatidylethanolamine (PE), phosphatidylserine (PS), and phosphatidylinositol (PI), respectively. Phospholipids are also characterized by different length and the degree of unsaturation of their fatty acyl chains. Variations in their properties have an impact on the membrane characteristics. This class of lipids is unevenly distributed between the different membranes in the cell [24, 47-49]. By contrast, in photosynthetic membranes of plants the major constituents are the nonphosphorus galactolipids divided mainly into two classes, monogalactosyldiacylglycerol (MGDG) and digalactosyldiacylglycerol (DGDG). Moreover, the nonphosphorous are also sulfolipids with sulfurcontaining lipid, sulfoquinovosyldiacylglycerol (SQDG) [50]. Both MGDG and DGDG and SQDG are synthesized exclusively in the chloroplasts [51-54]. Of the grana thylakoid membrane area, $20-30 \%$ is occupied by lipids, and the most part by proteins or photosynthetic protein complexes $[55,56]$. The thylakoid membranes in higher plants contain four glycerolipids: MGDG, DGDG, SQDG, and phosphatidylglycerol (PG) [57]. Of all chloroplast lipids, MGDG and DGDG can reach $52 \%$ and $26 \%$, respectively $[58,59]$. The exemplary composition of glycerolipids in the membranes of spinach chloroplasts and their thylakoids are presented in Table 2.
Table 2 Composition of lipids in the membranes of spinach chloroplasts and their thylakoids

\begin{tabular}{llllll}
\hline Composition of lipids & MGDG & DGDG & PC & PG & SL \\
\hline Outer membrane of chloroplast & 17 & 29 & 32 & 10 & 6 \\
Inner membrane of chloroplast & 49 & 30 & 6 & 8 & 5 \\
Thylakoids & 52 & 26 & 4.5 & 9.5 & 6.5
\end{tabular}

The proportion of the lipids was calculated as the weight of the percentage of fatty acids [59]

Plant sphingolipids are grouped into four classes: glycosyl inositolphosphoceramides (GIPC), glucosylceramides (GCer), ceramides (Cer), and free long-chain bases (LCB) $[60,61]$. They are built of a ceramide backbone composed of a long-chain base and a long-chain fatty acid matched by esterification. Both Cer and LCB can be phosphorylated and de-phosphorylated and Cer, additionally, glucosylated [62]. The composition of LCBs is mainly formed from phytosphingosine and its desaturated form, but others are also known, e.g., sphinganine and sphingenine [63]. The quantity of sphingolipids differs significantly depending on the plant species and tissues, but mostly reaches up to $10 \%$ of the total lipids in plants [64]. In the total amount of sphingolipids in the leaves of Arabidopsis, the ratios of GIPC:GCer:Cer:LCB were as follows 64:34:2:0.5\%, proving that GIPC and GCer were the most prevailing [65]. In the tonoplast, sphingolipids were detected in the range from 10 to $20 \%$ of the total membrane lipids [66, 67].

In plants, over 250 different sterols (phytosterols) have been identified. Among them most frequently are detected these belonging to 4-desmethylsterols, i.e., campesterol, stigmasterol, and sitosterol [68, 69]. Phytosterols can appear in the forms of free sterols, steryl esters, steryl glycosides, and acylated sterol glycosides [69].

\section{Lipids Organization in Membranes}

Fatty acids composition (with the proportion of saturated and unsaturated fatty acids) influences lipid composition (specific proportions) and organization in plant membranes. For example, the percentage content of lipids in the thylakoid membranes of green plants is as follows: MGDG 50\%, DGDG 25-30\%, SQDG 5-15\%, PG 5-15\% [70, 71]. The most popular fatty acids in the skeleton of plant galactolipids are 18:3/16:3 as 34:6 MGDG, 18:3/18:3 as 36:6 MGDG, 18:3/16:0 as 34:3 DGDG, and 18:3/18:3 DGDG in the approximate proportion: $80 \%, 16 \%, 16 \%, 70 \%$, respectively [72]. The biological membranes have different composition and contain the domains in their structure, called rafts, which are enriched in sphingolipids and sterols with reduced level of unsaturated fatty acids, esp. in phospholipids [73]. It means that rafts are structures of lesser fluidity than non-raft areas. 
Table 3 Lipids role in plants and their importance for humans [27, 40, 145, 146]

Role and importance of lipids

Plants Humans

The main structural components of biological membranes

Nutrients (improve the quantity and quality of oils for food and feed)

Provide fluidity and flexibility in the membranes

Medical/pharmaceutical application in health disorders

Serve as permeable and selective barriers to the external environment of cells (membrane trafficking)

Cosmetics (storage oils that accumulate in seeds used, e.g., soaps and cosmetics)

Modulate the physical properties of membranes (their surface charges,

Chemicals (storage oils used e.g., in paints and detergents) curvature, or clustering of proteins

Provide the integrity of cells and organelles (a hydrophobic barrier for the membrane)

Petrochemical industry (storage oils used as renewables for the production of biodiesel)

Key components in the establishment of organelle identity and dynamic

Components of enzyme system (e.g., xanthophyll cycle)

Mediators of interactions with numerous membrane-associated proteins (e.g., photosynthetic proteins)

Signal molecules regulating cell metabolism

Major regulators of many fundamental cellular processes (cell division, cell growth, and gene expression)

Energy storage compounds

Lipids perform many functions (Table 3). Among others, they influence performance, regulation, and physical properties of the membranes [74, 75], serve in the distribution, organization, and functioning of bilayer spanning proteins [76], are involved in compartmentalization of cells and organells and are integral components of the photosynthetic protein complexes of the electron transport chain [55]. Lipids can also form other structures, e.g., plastoglobules and stromules in the chloroplasts. Plastoglobules are lipid droplets enclosed in lipid monolayer, which is connected to the stroma leaflet of the thylakoid membrane. They can be found in high number in etioplasts and in plastids of senescent leaves. Stromules are tubular extensions of both chloroplast envelopes into the cytosol and filled with stroma, but deprived of thylakoids. The number of plastoglobules and stromules increases during environmental stresses [77, 78].

Lipids composition undergoes remodeling in the face of various physiological [30, 73, 79-82], and environmental conditions [83-85]. Moreover, the artificial membranes are composed and applied to broaden our understanding of nature. The model membranes mimicking the natural ones are dedicated to determining the network organization and reorganization of the molecules, structural and functional interactions and mechanisms in a simplified composition combined of a few different lipids (mostly two to five) (Table 4). Models of the artificially formed membranes are involved in the research on the molecular membrane architecture and structure [59, 86-88] based on the fluorescence [88] and microscopic techniques [87], including photosynthetic performance [89], xanthophyll cycle
Table 4 Proportion of lipids in the model membranes

\begin{tabular}{ll}
\hline Components proportion & References \\
\hline MGDG:DGDG & {$[59,86,87]$} \\
2:1 & {$[88]$} \\
MGDG:DGDG & \\
1:2 & {$[87,91]$} \\
MGDG:DGDG & \\
30:70 & {$[90]$} \\
PC:MGDG & \\
30.1:12.9 & {$[89]$} \\
MGDG:DGDG:SQDG:PG & \\
50:28:9:13 & \\
47:27:12:14 & {$[147]$} \\
MGDG:DGDG:SQDG:EPG & \\
40:30:15:15 & {$[92]$} \\
PC:PE:PI:PG:PA & \\
44:22:18:11:6 & {$[87]$} \\
DGDG:MGDG:SL & \\
73:24:2 & {$[88]$} \\
POPG:DGDG & \\
1:1 &
\end{tabular}

$M G D G$ monogalactosyldiacylglycerol, $D G D G$ digalactosyldiacylglycerol, $P C$ phosphatidylcholine, $S Q D G$ sulfoquinovosyldiacylglycerol, $P O P G$ 1-palmitoyl-2-oleoyl-sn-glycero-3-phosphocholine, EPG Egg phosphatidylglycerol; $P A$ phosphatidic acid, $S L$ sulfoquinovosyldiglyceride, $P I$ phosphatidylinositol, $P E$ phosphatidylethanolamine, $P G$ phosphatidylglycerol

analysis [87, 90, 91], and free radicals connection with the environmental stress in plants [92]. For example, the mixture of two lipids, MGDG:DGDG in 2:1 ratio can be 
applied as the model of plant lipids in thylakoids for the LHCII (light-harvesting complex) measurements [86].

Based on the type of the lipid phase produced by lipids in the aqueous systems, we differentiate the nonbilayer- and bilayer-forming lipids. Nonbilayer-forming lipids form the ordered solid phases and bilayer-forming ones-liquiddisordered phases [93] (Fig. 3). The nonbilayer-forming lipids possessing small polar head groups like MGDG and PE with elevated content of PUFAs form inverted micelles or tubular structures due to their cone-like shape and form an inverted hexagonal $\left(\mathrm{H}_{\mathrm{II}}\right)$ phase when dispersed in the aqueous solutions. The important functions of MGDG are to promote membrane stacking, stabilizing the inner membrane leaflet in grana disc [88] and conservation of photosynthetic energy [94]. Furthermore, the proportion of the thylakoid nonbilayer lipids are crucial, because the higher content of the MGDG is responsible for the membrane permeability and thermal stability of PSII [71].

The bilayer-forming lipids with large head groups, such as DGDG, SQDG, PC, PG, and the decreased content of long-chain PUFAs exhibit a cylindrical shape and form the lamellar L $\alpha$ phase [72, 93-96]. However, the increased ratio of DGDG to MGDG enhanced the stability of the thylakoid membrane [72]. Protein arrays are related with the phase transition of MGDG from a bilayer to a nonbilayer $\mathrm{H}_{\mathrm{II}}$ phase which was observed in the stress conditions, e.g., cold, low light [97], osmotic stress, and in fatty-acid mutants [98]. An association between lipids and protein organization is explained by the lateral membrane pressure hypothesis [99] known as 'force from lipids' (FFL) principle [100].

\section{Lipids in Xanthophyll Cycle}

The plants have developed the unique photoprotection mechanism, which prevents the excess absorption of light energy and consequently protects the photosynthetic apparatus from the oxidative damage. This process is called xanthophyll cycle [101]. In the xanthophyll cycle, the conversion of violaxanthin into zeaxanthin is done by violaxanthin deepoxidase (VDE) under high light [102-104].

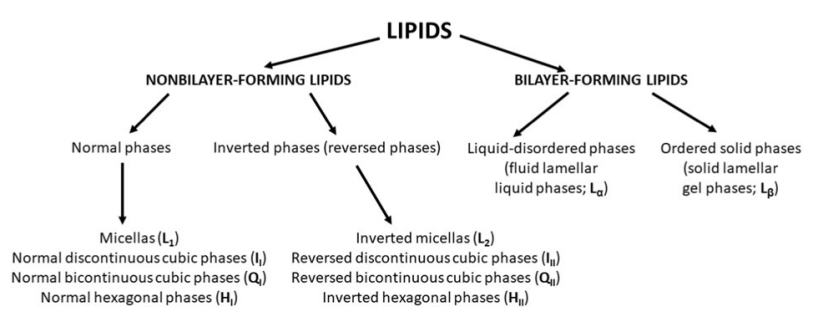

Fig. 3 Division of lipids based on the type of the lipid phase produced in aqueous systems
VDE localizes to the thylakoid lumen and is regulated by lumen $\mathrm{pH}[90,105]$ and by binding to MGDG. It means that the MGDG molecules can serve as the docking sites for the xanthophyll cycle enzymes. In chloroplasts, $\mathrm{H}_{\mathrm{II}}$ can be established by MGDG, but in vitro VDE can also be stimulated by binding to PE [106]. The xanthophyll cycle pigments are located in the hydrophobic region of membrane with an easy access to the $\mathrm{H}_{\mathrm{II}}$ phase [93, 107].

The studies concerning the location of the xanthophyll cycle in the transient membrane domain combined with LHCII, MGDG, VDE allowed to prove that MGDG have a crucial function in the stabilization of the structure of the LHCII protein in prevention its aggregation in PSII [71].

\section{Synthesis of Glycerolipids in Plants}

In plants, the most abundant class of lipids are glycerolipids, therefore first, their synthesis based on two pathways, then a brief view of the synthesis of PL, GL, TAG, and SL are presented.

Fatty acids are incorporated into glycerolipids in two different ways called the prokaryotic (plastidial) and the eukaryotic (cooperative) pathways located in the chloroplast and ER, respectively (Fig. 4) [15, 16, 108, 109]. The prokaryotic pathway is involved in PG synthesis in all plants, but in the glycerolipid synthesis only in 16:3 plants (which means 16 acyl carbons and 3 double bonds) in the $s n-2$ position of MGDG molecule [110]. Moreover, 16:3 plants are those which produce up to half of the MGDG in the plastidial pathway [111]. The eukaryotic pathway is involved in the glycerolipid synthesis in all plants, but mostly in 18:3 plants (which means 18 acyl carbons and 3 double bonds) in the $s n-2$ position of MGDG molecule [110]. Irregardless pathway type, biosynthesis of membrane lipids starts from the formation of PAs, which are utilized to produce plastidic lipids or phospholipids. Phosphatidic acid produced in the chloroplasts can be converted to diacylglycerol (DAG), which then serves as a precursor for plastidic lipid synthesis [45, 110, 112, 113]. PA is an intermediate molecule in the lipid synthesis and can be converted to and from PC and DAG because of the low energy requirements to remove them from membranes. PC could be a substrate for MGDG synthesis and DAG can be

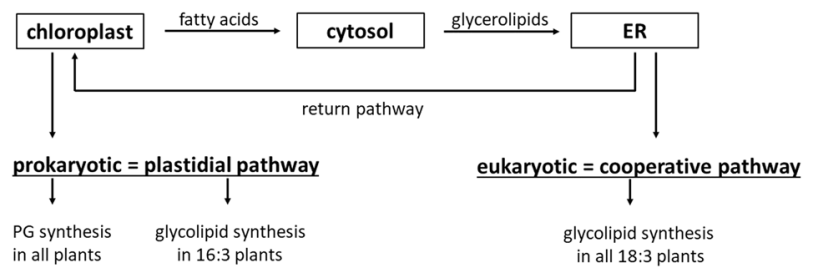

Fig. 4 Prokaryotic and eukaryotic pathways [45, 110, 113] 
synthesized de novo with fatty acids, then removed from other lipids or derived from TAG turnover [111].

The prokaryotic pathway synthesizes four classes of glycerolipids: three glycolipid classes, i.e., MGDG, DGDG, trigalactosyldiacylglycerol (TGDG), and one sulfolipid class, SQDG. In the plant cell, 95\% of fatty acids are produced by the plastidial fatty-acid synthase (FAS) belonging to the type I FAS [114]. First, coenzyme A (CoA) is converted into malonyl-CoA by acetyl-CoA carboxylase (ACCase) dependent on light [15]. Next, malonate is transferred to acyl carrier protein (ACP) by malonyl-CoA: ACP malonyltransferase (MCMT). Then, the activity of 3ketoacyl-ACP synthase 3, 1, and 2 (KAS III, I, and II, respectively) give the main products of fatty-acid de novo synthesis: 16:0-ACP and 18:1 $\Delta 9$-cis-ACP. Fatty-acid desaturation continues at high rate in the dark period [82].

By contrast, the eukaryotic pathway produces six phospholipid classes, i.e., phosphatidic acid (PA), PC, PE, PG, PI, and PS [115]. The eukaryotic pathway of 16:0/18:0 DAG moieties can produce around 20\% of total DGDG. During the life cycle of plants, an active lipid exchange between the chloroplast and ER occurs via the import of the DAG moiety of PCs from the ER to the chloroplast envelope where it contributes to the DAG pool used to synthesize plastidic lipids $[45,110,112,113]$.

Phosphatidylgycerol is synthesized in plastids, ER, and mitochondria and in chloroplasts it is predominantly synthesized via the prokaryotic pathway. Phosphatidylcholine, PE, and PI are synthesized in the ER membrane. Triacylglycerol is mainly synthesized in the ER and chloroplastic envelope membranes and accumulates within the membrane bilayer and subsequently forms lipid droplets in the cytosol $[116,117]$.

Moreover, some plant species show various proportions between pro- and eukaryotic pathways [15]. For example, in Arabidopsis leaves in controlled conditions, $\sim 50 \%$ of the chloroplastic glycolipids (MGDG, DGDG, and SQDG) are derived from the eukaryotic pathway, in which glycerolipids synthesized in the ER membrane are transferred to chloroplasts and converted into glycolipids [16, 118-120]. Other plants produce only one lipid, PG, in the prokaryotic pathway [15] and as the result of evolution [121], this pathway diminished in 18:3 plants [15]. Due to the insufficient information on prokaryotic pathway in 16:3 plants [110], the research of this pathway will provide data allowing to better understand the physiological significance of the lipid evolution in plants.

The phospholipid biosynthesis can be divided into the assembly of the phosphatidic acid (PA), formation free or activated DAG, which may be the sources for the biosynthesis of the cellular glycerolipids [122], and formation of the head group to form the whole glycerolipid molecule [47]. Both, PE and PC are synthesized in plants in two main steps. The first one is the conversion of serine to ethanolamine catalyzed by serine decarboxylase and the next one is the attachment of phosphocholine or phosphoethanolamine to the DAG backbone, catalyzed by aminoalcohol aminophosphotransferase [47]. Free fatty acids are exported from chloroplasts [123, 124].

The first step of galactolipid synthesis is the transfer of galactose from uridine diphosphate (UDP)-galactose (UDPGal) onto DAG in the presence of MGDG synthases. The second step is the transfer a galactose from UDP-Gal onto MGDG accompanied by digalactosyldiacylglycerol synthases. Both are localized to the outer envelope. Moreover, in order to introduce double bonds in MGDG and DGDG, different plastidial desaturases are synthesized in the inner $[52,53,115,125,126]$ and outer envelope [114].

Synthesis of TAGs can be driven by different pathways. The most straightforward seems to be the pathway in which the acyltransferases were required for successive acylation of medium-chain fatty acid in the $s n-2$ and $s n-3$ position of TAGs. Then, diacylglycerol acyltransferase (DGAT) incorporated, e.g., PC molecules, onto the membrane $[17,19,127-130]$. TAGs can also be synthesized by PC involvement by application of its entire DAG molecule or acyl-CoA may be used as an acyl donor [15]. TAG is formed from the conversion of the DAG and in reaction of acylation, DAG can be converted to TAG [108].

Biosynthesis of SQDG comprises three enzymatic steps. Uridine triphosphate (UTP) and glucose-1-phosphate under action of the unique stroma-localized UDP-Glc pyrophosphorylase UGP3 produced UDP-glucose (UDP-Glc) [131]. Then, UDP-Glc and sulfite are converted into UDPsulfoquinovose in the presence of stroma-localized UDPsulfoquinovose synthase (SQD1) [132]. Next, sulfoquinovose is transferred to DAG and catalyzed by SQD2 localized in the inner envelope [99].

Understanding of lipids metabolism is essential to study their regulatory role in the plant growth and development.

\section{Fatty Acids and Lipids Composition under Adverse Conditions}

Fatty acids and lipids are examined in the research on the reconstitution of membrane system and the effects of stress conditions. The disturbed balance of the membrane caused reorganization of the lipid bilayer [126]. The influence of adverse environment, e.g., nutrient deficiency (especially nitrogen and phosphate), temperature stress (heat, cold, and freezing), salinity and drought on membrane lipid composition was expansively proved (Table 5). Fatty acids and lipids composition were dependent on the length of time incubation in adverse conditions [41] or the level of the unfavorable agents [133]. The observed trends can vary from an increase in the total amount of each lipid class 


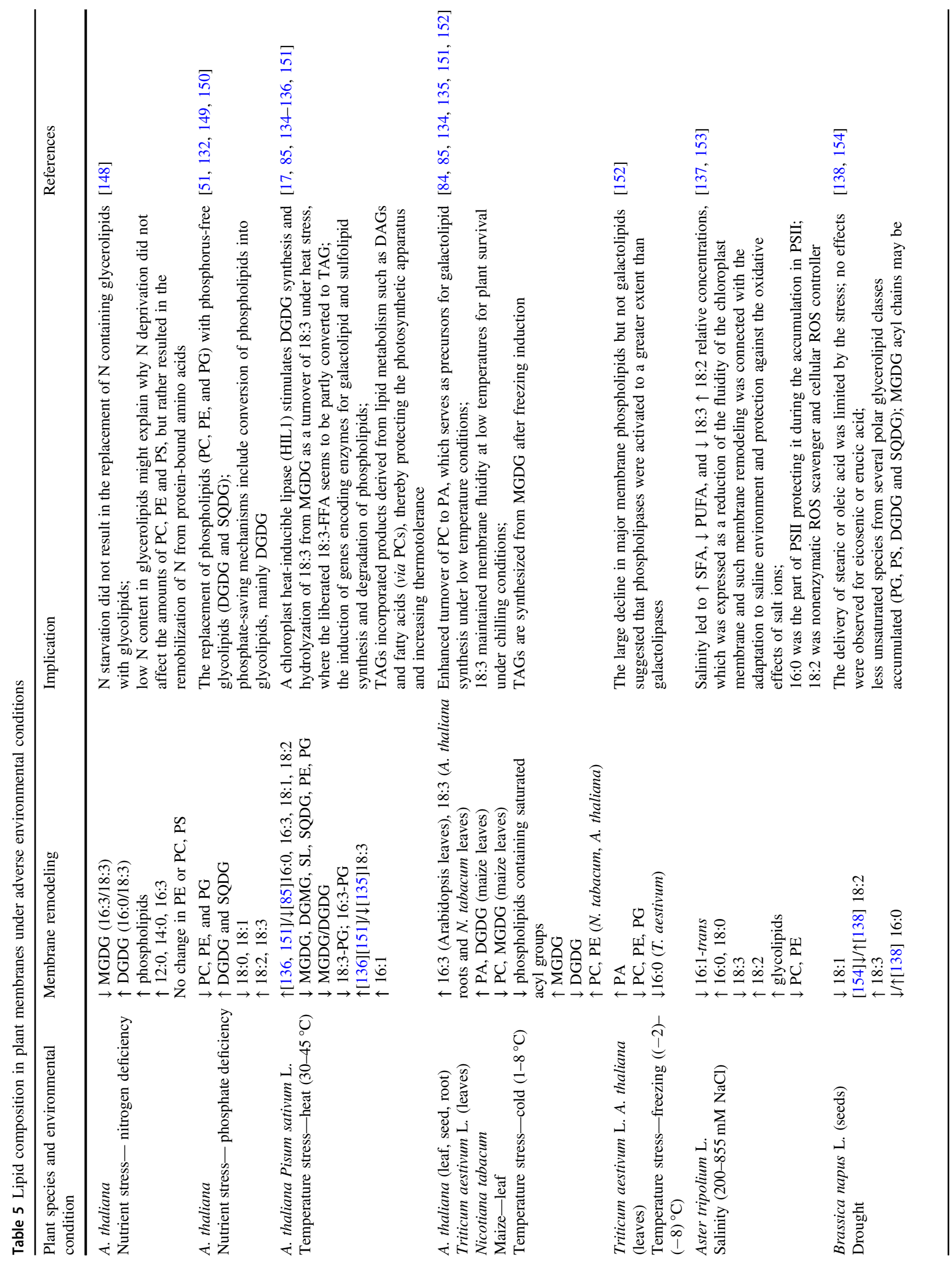




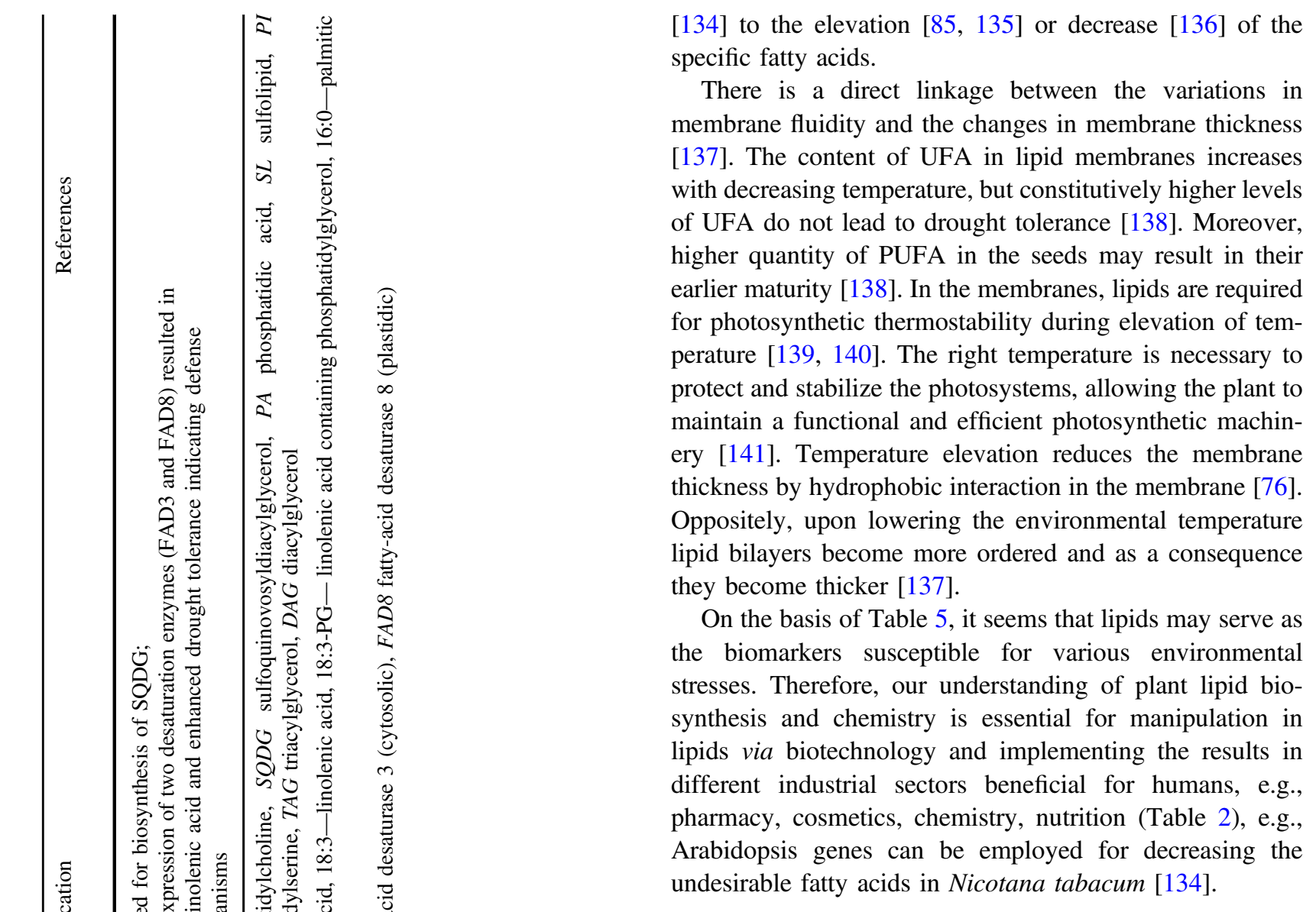

\section{Conclusions}

The biosynthesis and lipid composition (the ratio of saturated to unsaturated acids) of biomembranes play a key role in the functioning of plants. During their growth, plants adapted to the adverse conditions through the reorganization of lipid membranes resulting from the change in the fattyacid content and, consequently, the formation of lipids.

High level of lipids remodeling in plant membranes under different adverse conditions (e.g., nutrient deficiency, temperature stress, salinity, or drought) was proved. The elevation of UFA results in the membrane resistance to high temperatures, which allows plants to better adjust to the environmental changes. The crucial benefit resulting from the lipids research is that they could serve as the markers of plant physiological status. Moreover, better understanding of the biomembranes remodeling and lipids chemistry allows to generate changes desirable for different sectors of industry like pharmacy or agriculture and food science.

\section{Compliance with Ethical Standards}

Conflict of Interest The authors declare that they have no conflict of interest. 
Publisher's note Springer Nature remains neutral with regard to jurisdictional claims in published maps and institutional affiliations.

Open Access This article is licensed under a Creative Commons Attribution 4.0 International License, which permits use, sharing, adaptation, distribution and reproduction in any medium or format, as long as you give appropriate credit to the original author(s) and the source, provide a link to the Creative Commons license, and indicate if changes were made. The images or other third party material in this article are included in the article's Creative Commons license, unless indicated otherwise in a credit line to the material. If material is not included in the article's Creative Commons license and your intended use is not permitted by statutory regulation or exceeds the permitted use, you will need to obtain permission directly from the copyright holder. To view a copy of this license, visit http://creativecommons. org/licenses/by/4.0/.

\section{References}

1. Skupień, J., Wójtowicz, J., Kowalewska, Ł., Mazur, R., Garstka, M., Gieczewska, K., \& Mostowska, A. (2017). Dark-chilling induces substantial structural changes and modifies galactolipid and carotenoid composition during chloroplast biogenesis in cucumber (Cucumis sativus L.) cotyledons. Plant Physiology and Biochemistry, 111, 107-118.

2. Garstka, M., Venema, J. H., Rumak, I., Gieczewska, K., Rosiak, M., Koziol-Lipinska, J., \& Mostowska, A. (2007). Contrasting effect of dark-chilling on chloroplast structure and arrangement of chlorophyll-protein complexes in pea and tomato: Plants with a different susceptibility to non-freezing temperature. Planta, 226(5), 1165-1181.

3. Welti, R., Li, W., Li, M., Sang, Y., Biesiada, H., Zhou, H. E., \& Wang, X. (2002). Profiling membrane lipids in plant stress responses: role of phospholipase $\mathrm{D} \alpha$ in freezing-induced lipid changes in Arabidopsis. Journal of Biological Chemistry, 277 (35), 31994-32002.

4. Li, C., Cheng, X., Jia, Q., Song, H., Liu, X., Wang, K., \& Zhang, M. (2017). Investigation of plant species with identified seed oil fatty acids in Chinese literature and analysis of five unsurveyed Chinese endemic species. Frontiers in Plant Science, 8, 224.

5. Larsen, E., Kharazmi, A., Christensen, L. P., \& Christensen, S. B. (2003). An antiinflammatory galactolipid from rose hip (Rosa canina) that inhibits chemotaxis of human peripheral blood neutrophils in vitro. Journal of Natural Products, 66(7), 994-995.

6. Larsen, E., \& Christensen, L. P. (2007). Common vegetables and fruits as a source of 1,2-di-o-a-linolenoyl-3-o-b-d-galactopyranosyl-sn-glycerol, a potential anti-inflammatory and antitumor agent. Journal of Food Lipids, 14, 272-279.

7. Cateni, F., Falsone, G., Zilic, J., Bonivento, P., Zacchigna, M., Žigon, D. \& Altinier, G. (2004). Glyceroglycolipids from Euphorbia nicaeensis All. with antiinflamatory activity. Vincenzo Tortorella ARKIVOC, v, 54-65.

8. Kuriyama, I., Musumi, K., Yonezawa, Y., Takemura, M., Maeda, N., Iijima, H., \& Mizushina, Y. (2005). Inhibitory effects of glycolipids fraction from spinach on mammalian DNA polymerase activity and human cancer cell proliferation. Journal of Nutritional Biochemistry, 16, 594-601.

9. Maeda, N., Kokai, Y., Ohtani, S., Sahara, H., Kumamoto-Yonezawa, Y., Kuriyama, I., \& Mizushina, Y. (2008). Anti-tumor effect of orally administered spinach glycolipid fraction on implanted cancer cells, colon-26, in mice. Lipids, 43(8), 741-748.

10. Cateni, F., Bonivento, P., Procida, G., Zacchigna, M., Favretto, L. G., Scialino, G., \& Banfi, E. (2008). Chemoenzymatic synthesis and antimicrobial activity evaluation of monogalactosyl diglycerides. European Journal of Medicinal Chemistry, 43(1), 210-221.

11. Mishra, P. K., Singh, N., Ahmad, G., Dube, A., \& Maurya, R. (2005). Glycolipids and other constituents from Desmodium gangeticum with antileishmanial and immunomodulatory activities. Bioorganic and Medicinal Chemistry Letters, 15(20), 4543-4546.

12. Williams, C. M., \& Burdge, G. (2006). Long-chain n-3 PUFA: plant v. marine sources. Proceedings of the Nutrition Society, 65 (1), 42-50.

13. Konda, A. R., Nazarenus, T. J., Nguyen, H., Yang, J., Gelli, M., Swenson, S., \& Cahoon, E. B. (2020). Metabolic engineering of soybean seeds for enhanced vitamin E tocochromanol content and effects on oil antioxidant properties in polyunsaturated fatty acid-rich germplasm. Metabolic Engineering, 57, 63-73.

14. Leutou, A. S., Mccall, J. R., York, B., Govindapur, R. R., \& Bourdelais, A. J. (2020). Glycolipids and a polyunsaturated fatty acid methyl ester isolated from the marine Dinoflagellate Karenia mikimotoi. Marine Drugs, 18, 138.

15. Ohlrogge, J., \& Browse, J. (1995). Lipid biosynthesis. The Plant Cell, 7, 957-970.

16. Li-Beisson, Y., Neunzig, J., Lee, Y., \& Philippar, K. (2017). Plant membrane-protein mediated intracellular traffic of fatty acids and acyl lipids. Current Opinion in Plant Biology, 40, 138-146.

17. Reynolds, K. B., Taylor, M. C., Cullerne, D. P., Blanchard, C. L., Wood, C. C., Singh, S. P., \& Petrie, J. R. (2017). A reconfigured Kennedy pathway which promotes efficient accumulation of medium-chain fatty acids in leaf oils. Plant Biotechnology Journal, 15, 1397-1408.

18. Wernig, F., Boles, E., \& Oreb, M. (2020). De novo biosynthesis of 8-hydroxyoctanoic acid via a medium-chain length specific fatty acid synthase and cytochrome P450 in Saccharomyces cerevisiae. Metabolic Engineering Communications, 10, 1-8.

19. Iskandarov, U., Silva, J. E., Kim, H. J., Andersson, M., Cahoon, R. E., Mockaitis, K., \& Cahoon, E. B. (2017). A specialized diacylglycerol acyltransferase contributes to the extreme medium-chain fatty acid content of Cuphea seed oil. Plant Physiology, 174(1), 97-109.

20. Kamp, F., \& Hamilton, J. A. (2006). How fatty acids of different chain length enter and leave cells by free diffusion. Prostaglandins Leukotrienes and Essential Fatty Acids, 75, 149-159.

21. Guo, Z. H., Ye, Z. W., Haslam, R. P., Michaelson, L. V., Napier, J. A., \& Chye, M. L. (2019). Arabidopsis cytosolic acyl-CoAbinding proteins function in determining seed oil composition. Plant Direct, 3(12), 1-9.

22. Wang, D. Q. H., Portincasa, P., \& Neuschwander-Tetri, B. A. (2013). Steatosis in the liver. Comprehensive Physiology, 3(4), 1493-1532.

23. Castro, L. F. C., Tocher, D. R., \& Monroig, O. (2016). Longchain polyunsaturated fatty acid biosynthesis in chordates: Insights into the evolution of Fads and Elovl gene repertoire. Progress in Lipid Research, 62, 25-40.

24. Beare-Rogers, J., Dieffenbacher, A., \& Holm, J. V. (2001). International union of pure and applied chemistry joint committee of international union of nutritional sciences and IUPAC commission on Food * Lexicon of lipid nutrition (IUPAC Technical Report). Pure Appl. Chem, 73(4), 685-744.

25. Rustan, A. C., \& Drevon, C. A. (2005). Fatty acids: structures and properties. Encyclopedia of Life Sciences, John Wiley \& Sons, $1-7$.

26. Thelen, J. J., \& Ohlrogge, J. J. (2002). Metabolic engineering of fatty acid biosynthesis in plants. Metabolic Engineering, 4(1), 12-21.

27. Wang, T. Y., Liu, M., Portincasa, P., \& Wang, D. Q. H. (2013). New insights into the molecular mechanism of intestinal fatty 
acid absorption. European Journal of Clinical Investigation, 43 (11), 1203-1223.

28. Calder, P. C., \& Grimble, R. F. (2002). Polyunsaturated fatty acids, inflammation and immunity. European Journal of Clinical Nutrition, 56(3), 14-19.

29. Meléndez-Martínez, A. J., Mapelli-Brahm, P., Hornero-Méndez, D., \& Vicario, I. M. (2019). Chapter 1: Structures, nomenclature and general chemistry of carotenoids and their esters. In Food chemistry, function and analysis (pp. 3-50).

30. Peng, Z., Ruan, J., Tian, H., Shan, L., Meng, J., Guo, F., \& Li, X. (2020). The family of peanut fatty acid desaturase genes and a functional analysis of four $\omega-3$ AhFAD3 members. Plant Molecular Biology Reporter, 38, 209-221.

31. Keskin, C., \& Kaçar, S. (2013). Fatty acid composition of root and shoot samples of some Astragalus L. (Fabaceae) taxa growing in the east and southeast of Turkey. Turkish Journal of Biology, 37, 122-128.

32. Semenova, G. A. (1994). Particle regularity on thylakoid fracture faces is influenced by storage conditions 1. Canadian Journal of Bot, 73, 1676-1682.

33. Javidnia, K., Miri, R., Kamalinejad, M., Sarkarzadeh, H., \& Jamalian, A. (2004). Chemical composition of the essential oils of Anthemis altissima L. grown in Iran. Flavour and Fragrance Journal, 19, 213-216.

34. Bretagnolle, F., Matejicek, A., Gregoire, S., Reboud, X., \& Gaba, S. (2015). Determination of fatty acids content, global antioxidant activity and energy value of weed seeds from agricultural fields in France. Weed Research, 56, 78-95.

35. Motavalizadehkakhky, A., Shafaghat, A., Mehrzad, J., Shafaghatlonbar, M., Azimi, F., Ebrahimi, Z., \& Sakeri, A. (2016). Chemical composition of hexane extract of different parts of Anthemis talyschensis and its potential to use in sunscreen products. Journal of Chemical Health Risks, 6(3), 195-202.

36. Guimarães, R., Barros, L., Dueñas, M., Calhelha, R. C., Carvalho, A. M., Santos-Buelga, C., \& Ferreira, I. C. F. R. (2013). Nutrients, phytochemicals and bioactivity of wild Roman chamomile: a comparison between the herb and its preparations. Food Chemistry, 136, 718-725.

37. Khalil, M., Raila, J., Ali, M., Islam, K. M. S., Schenk, R., Krause, J. P., \& Rawel, H. (2012). Stability and bioavailability of lutein ester supplements from Tagetes flower prepared under food processing conditions. Journal of Functional Foods, 4(3), 602-610.

38. Zhang, C., Hua, Y., Li, X., Kong, X., \& Chen, Y. (2020). Key volatile off-flavor compounds in peas (Pisum sativum L.) and their relations with the endogenous precursors and enzymes using soybean (Glycine max) as a reference. Food Chemistry, $333,1-10$

39. Pavlovic, M., Kovacevic, N., Tzakou, O., \& Couladis, M. (2007). Components of cyclohexane extract of Anthemis triumfetti. Chemistry of Natural Compounds, 43(5), 420-421.

40. Özek, G., Özbek, M. U., \& Arslan, M. (2018). Lipid and essential oil constituents of cota hamzaoglui Özbek \& vural (Asteraceae). Journal of the Turkish Chemical Society, Section A: Chemistry, 5(3), 1361-1370.

41. Liping, W., Shen, W., Kazachkov, M., Chen, G., Chen, Q., Carlsson, A. S., \& Zou, J. (2012). Metabolic interactions between the lands cycle and the Kennedy pathway of glycerolipid synthesis in arabidopsis developing seedsw. Plant Cell, 24 (11), 4652-4669.

42. Vujisić, L., Vučković, I., Tešević, V., Doković, D., Ristić, M. S., Janaćknović, P., \& Milosavljević, S. (2006). Comparative examination of the essential oils of Anthemis ruthenica and A. arvensis wild growing in Serebia. Flavour and Fragrance Journal, 21, 458-461.

43. Paulin, O., Lassina, O., Robichaud, P.-P., Surette, M. E., Ouoba, P., Ouattara, L., \& Doiron, J. A. (2018). Extraction of vegetable oil from Cissus populnea Guill and Perr. seeds and determination of its fatty acids content ENRECA (Enhancement and capacity building in West Africa) view project crop-preserving and food safety using natural plant products in smal. International Journal of Food Science and Nutrition, 3(4), 80-83.

44. Sinkovič, L., Kokalj, D., Vidrih, R., \& Meglič, V. (2020). Milling fractions fatty acid composition of common (Fagopyrum esculentum Moench) and tartary (Fagopyrum tataricum (L.) Gaertn) buckwheat. Journal of Stored Products Research, 85, $1-5$.

45. Kunst, L., Browse, J., \& Somerville, C. (1989). A mutant of arabidopsis deficient in desaturation of palmitic acid in leaf lipids. Plant Physiology, 90(3), 943-947.

46. MacDonald, G. E., Lada, R. R., Caldwell, C. D., Udenigwe, C., \& MacDonald, M. T. (2019). Potential roles of fatty acids and lipids in postharvest needle abscission physiology. American Journal of Plant Sciences, 10(06), 1069-1089.

47. Nakamura, Y. (2017). Plant phospholipid diversity: emerging functions in metabolism and protein-lipid interactions. Trends in Plant Science, 22(12), 1027-1040.

48. Mackender, R. O., \& Leech, R. M. (1974). The galactolipid, phospholipid, and fatty acid composition of the chloroplast envelope membranes of Vicia faba. L. Plant Physiology, 53(3), 496-502.

49. Micoogullari, Y., Basu, S. S., Ang, J., Weisshaar, N., Schmitt, N. D., Abdelmoula, W. M., \& Hanna, J. (2019). Dysregulation of very long chain fatty acid metabolism causes membrane saturation and induction of the unfolded protein response running title: VLCFAs and protein quality control. Molecular Biology of the Cell, 31(1), 1-17.

50. Ben Hamed, K., Ben Youssef, N., Ranieri, A., Zarrouk, M., \& Abdelly, C. (2005). Changes in content and fatty acid profiles of total lipids and sulfolipids in the halophyte Crithmum maritimum under salt stress. Journal of Plant Physiology, 162, 599-602.

51. Härtel, H., Dörmann, P., \& Benning, C. (2000). DGD1independent biosynthesis of extraplastidic galactolipids after phosphate deprivation in Arabidopsis. Proc. Natl. Acad. Sci., 97 (19), 10649-10654.

52. Awai, K., Maré Chal, E., Block, M. A., Brun, D., Masuda, T., Shimada, H., \& Joyard, J. (2001). Two types of MGDG synthase genes, found widely in both 16:3 and 18:3 plants, differentially mediate galactolipid syntheses in photosynthetic and nonphotosynthetic tissues in Arabidopsis thaliana. Proc. Natl. Acad. Sci., 98(19), 10960-10965.

53. Kobayashi, K., Kondo, M., Fukuda, H., Nishimura, M., \& Ohta, H. (2007). Galactolipid synthesis in chloroplast inner envelope is essential for proper thylakoid biogenesis, photosynthesis, and embryogenesis. Proc. Natl. Acad. Sci., 104(43), 17216-17221.

54. Pugh, C. E., Roy, A. B., Hawkest, T., \& Harwood, J. L. (1995). A new pathway for the synthesis of the plant sulpholipid, sulphoquinovosyldiacylglycerol. Biochem. J, 309, 513-519.

55. Kirchhoff, H., Haase, W., Wegner, S., Danielsson, R., Ackermann, R., \& Albertsson, P. A. (2007). Low-light-induced formation of semicrystalline photosystem II arrays in higher plant chloroplasts. Biochemistry, 46(39), 11169-11176.

56. Kirchhoff, H. (2008). Molecular crowding and order in photosynthetic membranes. Trends in Plant Science, 13(5), 201-207.

57. Xu, Y. N., Wang, Z. N., Jiang, G. Z., Li, L. B., \& Kuang, T. Y. (2003). Effect of various temperatures on phosphatidylglycerol biosynthesis in thylakoid membranes. Physiologia Plantarum, 118(1), 57-63.

58. Kobayashi, K., Endo, K., \& Wada, H. (2017). Specific distribution of phosphatidylglycerol to photosystem complexes in the thylakoid membrane. Frontiers in Plant Science, 8, 1-7.

59. Block, M. A., Dorne, A.-J., Joyard, J., \& Douce, R. (1983). Preparation and characterization of membrane fractions enriched 
in outer and inner envelope membranes from spinach chloroplasts 11. Biochemical characterization. Journal of Biological Chemistry, 258(21), 13281-13286.

60. Mamode Cassim, A., Gouguet, P., Gronnier, J., Laurent, N., Germain, V., Grison, M., \& Mongrand, S. (2019). Plant lipids: key players of plasma membrane organization and function. Progress in Lipid Research, 73, 1-27.

61. Sato, M., Nagano, M., J In, S., Miyagi, A., Yamaguchi, M., KawaiYamada, M., \& Ishikawa, T. (2020). Plant-unique cis/trans isomerism of long-chain base unsaturation is selectively required for aluminum tolerance resulting from glucosylceramide-dependent plasma membrane fluidity. Plants, 9(19), 1-14.

62. Michaelson, L. V., Napier, J. A., Molino, D., \& Faure, J. D. (2016). Plant sphingolipids: their importance in cellular organization and adaption. Biochimica et Biophysica Acta - Molecular and Cell Biology of Lipids, 1861, 1329-1335.

63. Karlsson, K. A. (1970). Sphingolipid long chain bases. Lipids, 5 (11), 878-891.

64. Lynch, D. V., \& Dunn, T. M. (2004). An introduction to plant sphingolipids and a review of recent advances in understanding their metabolism and function. New Phytologist, 161, 677-702.

65. Markham, J. E., Li, J., Cahoon, E. B., \& Jaworski, J. G. (2006). Separation and identification of major plant sphingolipid classes from leaves. Journal of Biological Chemistry, 281(32), 22684-22694.

66. Moreau, P., Bessoule, J. J., Mongrand, S., Testet, E., Vincent, P., \& Cassagne, C. (1998). Lipid trafficking in plant cells. Progre, 37(6), 371-391.

67. Warnecke, D., \& Heinz, E. (2003). Recently discovered functions of glucosylceramides in plants and fungi. Cellular and Molecular Life Sciences, 60, 919-941.

68. Aikihsa T., K. W. T. T. (1991). Physiology and biochemistry of sterols. In G. W. Patterson \& W. D. Nes (Ed.). Champaign, IL: American Oil Chemical Society.

69. Pelillo, M., Iafelice, G., Marconi, E., \& Caboni, M. F. (2003). Identification of plant sterols in hexaploid and tetraploid wheats using gas chromatography with mass spectrometry. Rapid Communications in Mass Spectrometry, 17(20), 2245-2252.

70. Garab, G., Lohner, K., Laggner, P., \& Farkas, T. (2000). Selfregulation of the lipid content of membranes by non-bilayer lipids: A hypothesis. Trends in Plant Science, 5(11), 489-494.

71. Dlouhý, O., Kurasová, I., Karlický, V., Javornik, U., Šket, P., Petrova, N. Z., \& Garab, G. (2020). Modulation of non-bilayer lipid phases and the structure and functions of thylakoid membranes: effects on the water-soluble enzyme violaxanthin deepoxidase. Scientific Reports, 10, 11959.

72. Chen, J., Burke, J. J., Xin, Z., Xu, C., \& Velten, J. (2006). Characterization of the Arabidopsis thermosensitive mutant atts02 reveals an important role for galactolipids in thermotolerance. Plant, Cell and Environment, 29(7), 1437-1448.

73. Mongrand, S., Stanislas, T., Bayer, E. M. F., Lherminier, J., \& Simon-Plas, F. (2010). Membrane rafts in plant cells. Trends in Plant Science, 15(12), 656-663.

74. Noack, L. C., \& Jaillais, Y. (2020). Annual review of plant biology functions of anionic lipids in plants. 71, 71-102.

75. Kim, H. U. (2020). Lipid metabolism in plants. Plants, 9(871), $1-4$.

76. Epand, R. M. (1998). Lipid polymorphism and protein-lipid interactions. Biochimica et Biophysica Acta, 1376, 353-368.

77. Hanson, M. R., \& Hines, K. M. (2018). Stromules: Probing formation and function. Plant Physiology, 176, 128-137.

78. Mortimer, C. L., Misawa, N., Perez-Fons, L., Robertson, F. P., Harada, H., Bramley, P. M., \& Fraser, P. D. (2017). The formation and sequestration of nonendogenous ketocarotenoids in transgenic Nicotiana glauca. Plant Physiology, 173, 1617-1635.
79. Maatta, S., Scheu, B., Roth, M. R., Tamura, P., Li, M., Williams, T. D., \& Welti, R. (2012). Levels of Arabidopsis thaliana leaf phosphatidic acids, phosphatidylserines, and most trienoatecontaining polar lipid molecular species increase during the dark period of the diurnal cycle. Frontiers in Plant Science, 3(49), 1-12.

80. Nakamura, Y., Andrés, F., Kanehara, K., Liu, Y. C., Dörmann, P., \& Coupland, G. (2014). Arabidopsis florigen FT binds to diurnally oscillating phospholipids that accelerate flowering. Nature Communications, 5, 1-7.

81. Miquel, M., \& Browse, J. (1992). Arabidopsis mutants deficient in polyunsaturated fatty acid synthesis. The Journal of BIiological Chemistry, 267(3), 1502-1509.

82. Mou, Z., He, Y., Dai, Y., Liu, X., \& Li, J. (2000). Deficiency in fatty acid synthase leads to premature cell death and dramatic alterations in plant morphology. The Plant Cell, 12, 405-417.

83. Tjellström, H., Yang, Z., Allen, D. K., \& Ohlrogge, J. B. (2012). Rapid kinetic labeling of Arabidopsis cell suspension cultures: implications for models of lipid export from plastids. Plant Physiology, 158, 601-611.

84. Popov, V. N., Antipina, O. V., Pchelkin, V. P., \& Tsydendambaev, V. D. (2017). Changes in fatty acid composition of lipids in chloroplast membranes of tobacco plants during cold hardening. Russian Journal of Plant Physiology, 64(2), 156-161.

85. Gu, Y., He, L., Zhao, C., Wang, F., Yan, B., Gao, Y., \& Xu, J. (2017). Biochemical and transcriptional regulation of membrane lipid metabolism in maize leaves under low temperature. Frontiers in Plant Science, 8(2053), 1-13.

86. Janik, E., Bednarska, J., Zubik, M., Puzio, M., Luchowski, R., Grudzinski, W., \& Gruszecki, W. I. (2013). Molecular architecture of plant thylakoids under physiological and light stress conditions: A study of lipid-light-harvesting complex II model membranes. Plant Cell, 25(6), 2155-2170.

87. Sprague, S. G., \& Staehelin, L. A. (1984). Effects of reconstitution method on the structural organization of isolated chloroplast membrane lipids. BBA - Biomembranes, 777, 306-322.

88. Seiwert, D., Witt, H., Ritz, S., Janshoff, A., \& Paulsen, H. (2018). The nonbilayer lipid MGDG and the major lightharvesting complex (LHCII) promote membrane stacking in supported lipid bilayers. Biochemistry, 57, 2278-2288.

89. Duchêne, S., \& Siegenthaler, P.-A. (2000). Do glycerolipids display lateral heterogeneity in the thylakoid membrane? Lipids, 35(7), 739-744.

90. Latowski, D., Kruk, J., Burda, K., Skrzynecka-Jaskier, M., Kostecka-Gugala, A., \& Strzalka, K. (2002). Kinetics of violaxanthin de-epoxidation by violaxanthin de-epoxidase, a xanthophyll cycle enzyme, is regulated by membrane fluidity in model lipid bilayers. European Journal of Biochemistry, 269 (18), 4656-4665.

91. Szilágyi, A., Selstam, E., \& Åkerlund, H. E. (2008). Laurdan fluorescence spectroscopy in the thylakoid bilayer: the effect of violaxanthin to zeaxanthin conversion on the galactolipid dominated lipid environment. Biochimica et Biophysica Acta Biomembranes, 1778, 348-355.

92. Barclay, K. D., \& Mckersie, B. D. (1994). Peroxidation reactions in plant membranes: effects of free fatty acids. Lipids, 29(12), 877-882.

93. Goss, R., \& Latowski, D. (2020). Lipid dependence of xanthophyll cycling in higher plants and Algae. Frontiers in Plant Science, 11(455), 1-22.

94. Kirchhoff, H. (2018). Structure-function relationships in photosynthetic membranes: Challenges and emerging fields. Plant Science, 266, 76-82.

95. Kobayashi, K. (2016). Role of membrane glycerolipids in photosynthesis, thylakoid biogenesis and chloroplast development. Journal of Plant Research, 129(4), 565-580. 
96. Su, K., Bremer, D. J., Jeannotte, R., Welti, R., \& Yang, C. (2009). Membrane Lipid Composition and heat tolerance in coolseason Turfgrasses, including a Hybrid Bluegrass. Journal of the American Society for Horticultural science, 134(5), 511-520.

97. Semenova, G. A. (1995). Particle regularity on thylakoid fracture faces is influenced by storage conditions. Canadian Journal of Botany, 73(10), 1676-1682.

98. Tsvetkova, N. M., Apostolova, E. L., Brain, A. P. R., Patrick Williams, W., \& Quinn, P. J. (1995). Factors influencing PS II particle array formation in Arabidopsis thaliana chloroplasts and the relationship of such arrays to the thermostability of PS II. BBA. Bioenergetics, 1228, 201-210.

99. Yu, B., Xu, C., \& Benning, C. (2002). Arabidopsis disrupted in SQD2 encoding sulfolipid synthase is impaired in phosphatelimited growth. Proc. Natl. Acad. Sci., 99(8), 5732-5737.

100. Anishkin, A., Loukin, S. H., Teng, J., \& Kung, C. (2014). Feeling the hidden mechanical forces in lipid bilayer is an original sense. Proc. Natl. Acad. Sci., 111(22), 7898-7905.

101. Xie, Y., Jiang, S., Li, M., Guo, Y., Cheng, Y., Qian, H., \& Yao, W. (2019). Evaluation on the formation of lipid free radicals in the oxidation process of peanut oil. $L W T, 104,24-29$.

102. Gruszecki, W. I., \& Krupa, Z. (1993). LHCII, the major lightharvesting pigment-protein complex is a zeaxanthin epoxidase. BBA - Bioenergetics, 1144, 97-101.

103. Cooney, L. J., Logan, B. A., Walsh, M. J. L., Nnatubeugo, N. B., Reblin, J. S., \& Gould, K. S. (2018). Photoprotection from anthocyanins and thermal energy dissipation in senescing red and green Sambucus canadensis peduncles. Environmental and Experimental Botany, 148, 27-34.

104. Xie, X., Gu, W., Gao, S., Lu, S., Li, J., Pan, G., \& Shen, S. (2013). Alternative electron transports participate in the maintenance of violaxanthin de-epoxidase activity of Ulva sp. under low irradiance. PLOS ONE, 8(11), 78211.

105. Li, X.-P., Bjo, O., Rkman, È., Shih, C., Grossman, A. R., Rosenquist, M., \& Niyogi, K. K. (2000). A pigment-binding protein essential for regulation of photosynthetic light harvesting. Nature, 403, 391-395.

106. Olchawa-Pajor, M., Bojko, M., Strzalka, W., Strzalka, K., \& Latowski, D. (2019). Violaxanthin conversion by recombinant diatom and plant de-epoxidases, expressed in Escherichia coli-a comparative analysis. Acta Biochimica Polonica, 66(3), 249-255.

107. Goss, R., Latowski, D., Grzyb, J., Vieler, A., Lohr, M., Wilhelm, C., \& Strzalka, K. (2007). Lipid dependence of diadinoxanthin solubilization and de-epoxidation in artificial membrane systems resembling the lipid composition of the natural thylakoid membrane. Biochimica et Biophysica Acta - Biomembranes, 1768(1), 67-75.

108. Li-Beisson, Y., Shorrosh, B., Beisson, F., Andersson, M. X., Arondel, V., Bates, P. D., \& Ohlrogge, J. (2013). Acyl-Lipid Metabolism. The Arabidopsis Book, 11, 1-70.

109. Li, Q., Zheng, Q., Shen, W., Cram, D., Brian Fowler, D., Wei, Y., \& Zou, J. (2015). Understanding the biochemical basis of temperature-induced lipid pathway adjustments in plants. Plant Cell, 27, 8-103.

110. Negi, J., Munemasa, S., Song, B., Tadakuma, R., Fujita, M., Azoulay-Shemer, T., \& Iba, K. (2018). Eukaryotic lipid metabolic pathway is essential for functional chloroplasts and $\mathrm{CO}_{2}$ and light responses in Arabidopsis guard cells. Proc. Natl. Acad. Sci., 115(36), 9038-9043.

111. Karki, N., Johnson, B. S., \& Bates, P. D. (2019). Metabolically distinct pools of phosphatidylcholine are involved in trafficking of fatty acids out of and into the chloroplast for membrane production. The Plant Cell, 31, 2768-2788.

112. Wang, L., Kazachkov, M., Shen, W., Bai, M., Wu, H., \& Zou, J. (2014). Deciphering the roles of Arabidopsis LPCAT and PAH in phosphatidylcholine homeostasis and pathway coordination for chloroplast lipid synthesis. Plant Journal, 80(6), 965-976.
113. Miquel, M., \& Browse, J. (1992). Arabidopsis mutants deficient in polyunsaturated fatty acid synthesis: Biochemical and genetic characterization of a plant oleoyl-phosphatidylcholine desaturase. Journal of Biological Chemistry, 267(3), 1502-1509.

114. Hölzl, G., \& Dörmann, P. (2019). Chloroplast lipids and their biosynthesis. Annual Review of Plant Biology, 70, 51-81.

115. Jarvis, P., Dörmann, P., Peto, C. A., Lutes, J., Benning, C., \& Chory, J. (2000). Galactolipid deficiency and abnormal chloroplast development in the Arabidopsis MGD synthase 1 mutant. Proc. Natl. Acad. Sci., 97(14), 8175-8179.

116. Troncoso-Ponce, M. A., Cao, X., Yang, Z., \& Ohlrogge, J. B. (2013). Lipid turnover during senescence. Plant Science, 205-206, 13-19.

117. Chapman, K. D., \& Ohlrogge, J. B. (2012). Compartmentation of triacylglycerol accumulation in plants. Journal of Biological Chemistry, 287, 2288-2294.

118. Fan, J., Zhai, Z., Yan, C., \& Xu, C. (2015). Arabidopsis trigalactosyldiacylglycerol5 interacts with TGD1, TGD2, and TGD4 to facilitate lipid transfer from the endoplasmic reticulum to plastids. Plant Cell, 27, 2941-2955.

119. Nakamura, Y., Koizumi, R., Shui, G., Shimojima, M., Wenk, M. R., Ito, T., \& Ohtad, H. (2009). Arabidopsis lipins mediate eukaryotic pathway of lipid metabolism and cope critically with phosphate starvation. Proc. Natl. Acad. Sci., 106(49), 20978-20983.

120. Kelly, A. A., Kalisch, B., Hölzl, G., Schulze, S., Thiele, J., Melzer, M., \& Dörmann, P. (2016). Synthesis and transfer of galactolipids in the chloroplast envelope membranes of Arabidopsis thaliana. Proc. Natl. Acad. Sci., 113(38), 10714-10719.

121. Goss, R., Wilhelm, C., \& Gyözö, G. (2000). Organization of the pigment molecules in the chlorophyll $\mathrm{a} / \mathrm{b} / \mathrm{c}$ containing alga Mantoniella squamata (Prasinophyceae) studied by means of absorption, circular and linear dichroism spectroscopy. Biochimica et Biophysica Acta, 1457, 190-199.

122. Williams, J. P., Imperial, V., Khan, M. U., \& Hodson, J. N. (2000). The role of phosphatidylcholine in fatty acid exchange and desaturation in Brassica napus L. leaves. Biochemical Journal, 349(1), 127-133.

123. Jessen, D., Roth, C., Wiermer, M., \& Fulda, M. (2015). Two activities of long-chain acyl-coenzyme a synthetase are involved in lipid trafficking between the endoplasmic reticulum and the plastid in arabidopsis. Plant Physiology, 167, 351-366.

124. Schnurr, J. A., Shockey, J. M., De Boer, G. J., \& Browse, J. A. (2002). Fatty acid export from the chloroplast. Molecular characterization of a major plastidial acyl-coenzyme A synthetase from Arabidopsis. Plant Physiology, 129, 1700-1709.

125. Shimojima, M., Ohta, H., Iwamatsu, A., Masuda, T., Shioi, Y., \& Takamiya, K. I. (1997). Cloning of the gene for monogalactosyldiacylglycerol synthase and its evolutionary origin. Proc. Natl. Acad. Sci., 94, 333-337.

126. Mazur, R., Mostowska, A., Szach, J., Gieczewska, K., Wójtowicz, J., Bednarska, K., \& Kowalewska, Ł. (2019). Galactolipid deficiency disturbs spatial arrangement of the thylakoid network in Arabidopsis thaliana plants. Journal of Experimental Botany, 70(18), 4689-4703.

127. Kunst, L., Browse, J., \& Somerville, C. (1989). Enhanced thermal tolerance in a mutant of Arabidopsis deficient in palmitic acid unsaturation. Plant Physiol, 91, 401-408.

128. Kim, H. U., \& Huang, A. H. C. (2004). Plastid lysophosphatidyl acyltransferase is essential for embryo development in Arabidopsis. Plant Physiology, 134, 1206-1216.

129. Yu, B., Wakao, S., Fan, J., \& Benning, C. (2004). Loss of plastidic lysophosphatidic acid acyltransferase causes embryo-lethality in Arabidopsis. Plant and Cell Physiology, 45(5), 503-510.

130. Bacher, A., Eberhardt, S., Fischer, M., Kis, K., \& Richter, G. (2000). Biosynthesis of vitamin B2 (Riboflavin). Annual Review of Nutrition, 20, 153-167. 
131. Okazaki, Y., Shimojima, M., Sawada, Y., Toyooka, K., Narisawa, T., Mochida, K., \& Saito, K. (2009). A chloroplastic UDP-glucose pyrophosphorylase from Arabidopsis is the committed enzyme for the first step of sulfolipid biosynthesis. Plant Cell, 21, 892-909.

132. Essigmann, B., Güler, S., Narang, R. A., Linke, D., \& Benning, C. (1998). Phosphate availability affects the thylakoid lipid composition and the expression of SQD1, a gene required for sulfolipid biosynthesis in Arabidopsis thaliana. Plant Biology, 95, 1950-1955.

133. Noblet, A., Leymarie, J., \& Bailly, C. (2017). Chilling temperature remodels phospholipidome of Zea mays seeds during imbibition. Scientific Reports, 7(1), 1-12.

134. Kodama, H., Horiguchi, C., Nishiuchi, T., Nishimura, M., \& Iba, K. (1995). Fatty acid desaturation during chilling acclimation 1s one of the factors lnvolved in conferring low-temperature tolerance to young tobacco leaves. Plant Physiol, 107, 1177-1185.

135. Okuley, J., Lightner, J., Feldmann, K., Yadav, N., Lark, E., \& Browse, J. (1994). Arabidopsis FAD2 gene encodes the enzyme that is essential for polyunsaturated lipid synthesis. Plant Cell, 6 (1), 147-158.

136. Mueller, S. P., Unger, M., Guender, L., Fekete, A., \& Mueller, M. J. (2017). Phospholipid: diacylglycerol acyltransferasemediated triacylglyerol synthesis augments basal thermotolerance. Plant Physiology, 175(1), 486-497.

137. Duarte, B., Matos, A. R., Marques, J. C., \& Caçador, I. (2018). Leaf fatty acid remodeling in the salt-excreting halophytic grass Spartina patens along a salinity gradient. Plant Physiology and Biochemistry, 124, 112-116.

138. Hatzig, S. V., Nuppenau, J. N., Snowdon, R. J., \& Schieß1, S. V. (2018). Drought stress has transgenerational effects on seeds and seedlings in winter oilseed rape (Brassica napus L.). BMC Plant Biology, 18, 297

139. Falcone, D. L., Ogas, J. P., \& Somerville, C. R. (2004). Regulation of membrane fatty acid composition by temperature in mutants of Arabidopsis with alterations in membrane lipid composition. BMC Plant Biology, 4, 1-45.

140. MacDonald, G. E., Lada, R. R., Caldwell, C. D., Udenigwe, C., $\&$ MacDonald, M. (2020). Lipid and fatty acid changes linked to postharvest needle abscission in balsam fir, Abies balsamea. Trees - Structure and Function, 34, 297-305.

141. Kobayashi, K., Osawa, Y., Yoshihara, A., Shimojima, M., \& Awai, K. (2020). Relationship between glycerolipids and photosynthetic components during recovery of thylakoid membranes from nitrogen starvation-induced attenuation in Synechocystis sp. PCC 6803. Frontiers in Plant Science, 11(432), 1-13.

142. Pata, M. O., Hannun, Y. A., \& Ng, C. K. Y. (2009). Plant sphingolipids: Decoding the enigma of the Sphinx. New Phytologist, 185, 611-630.
143. Bakoglu, A., Kokten, K., \& Kilic, O. (2017). Seed fatty acid composition of some Fabaceae taxa from Turkey, a chemotaxonomic approach. Progress in Nutrition, 19(1), 86-91.

144. Ayaz Faik, A., Huseyin, I., Sema, H.-A., \& Nursen, A.-K. (2016). Achene fatty acid composition in the Tribe Anthemideae (Asteraceae). Romanian Biotechnological Letters, 21, 11576-11584.

145. Marsiñach, M. S., \& Cuenca, A. P. (2019). The impact of sea buckthorn oil fatty acids on human health. Lipids in Health and Disease, 18(1), 1-11.

146. Bansal, S., Kim, H. J., Na, G. N., Hamilton, M. E., Cahoon, E. B., Lu, C., \& Durrett, T. P. (2018). Towards the synthetic design of camelina oil enriched in tailored acetyl-triacylglycerols with medium-chain fatty acids. Journal of Experimental Botany, 69 (18), 4395-4402.

147. Hincha, D. K. (2008). Effects of $\alpha$-tocopherol (vitamin E) on the stability and lipid dynamics of model membranes mimicking the lipid composition of plant chloroplast membranes. FEBS Letters, 582(25-26), 3687-3692.

148. Gaude, N., Bréhélin, C., Tischendorf, G., Kessler, F., \& Dörmann, P. (2007). Nitrogen deficiency in Arabidopsis affects galactolipid composition and gene expression and results in accumulation of fatty acid phytyl esters. Plant Journal, 49(4), 729-739.

149. Jouhet, J., Maréchal, E., Baldan, B., Bligny, R., Joyard, J., \& Block, M. A. (2004). Phosphate deprivation induces transfer of DGDG galactolipid from chloroplast to mitochondria. Journal of Cell Biology, 167(5), 863-874.

150. Michaud, M., Gros, V., Tardif, M., Brugière, S., Ferro, M., Prinz, W. A., \& Jouhet, J. (2016). AtMic60 is involved in plant mitochondria lipid trafficking and is part of a largecomplex. Current Biology, 26(5), 627-639.

151. Degenkolbe, T., Giavalisco, P., Zuther, E., Seiwert, B., Hincha, D. K., \& Willmitzer, L. (2012). Differential remodeling of the lipidome during cold acclimation in natural accessions of Arabidopsis thaliana. Plant Journal, 72, 972-982.

152. Nejadsadeghi, L., Maali-Amiri, R., Zeinali, H., Ramezanpour, S., \& Sadeghzade, B. (2015). Membrane fatty acid compositions and cold-induced responses in tetraploid and hexaploid wheats. Molecular Biology Reports, 42(2), 363-372.

153. Duarte, B., Cabrita, M. T., Gameiro, C., Matos, A. R., Godinho, R., Marques, J. C., \& Caçador, I. (2017). Disentangling the photochemical salinity tolerance in Aster tripolium L.: connecting biophysical traits with changes in fatty acid composition. Plant Biology, 19, 239-248.

154. Zhang, J., Kenworthy, K., Unruh, J. B., Erickson, J., \& MacDonald, G. (2017). Changes of leaf membrane fatty acid composition and saturation level of warm-season turfgrass during drought stress. Crop Science, 57(5), 2843-2851. 